\title{
A Three-Year Study on Acute Poisoning Cases Brought for Medico-Legal Autopsy in a North-Eastern City of India
}

This article was published in the following Dove Press journal: Open Access Emergency Medicine

\author{
Oli Goswami' \\ Putul Mahanta (iD ${ }^{2}$ \\ Deepjyoti Kalita ${ }^{3}$ \\ Ranjumoni Konwar ${ }^{4}$ \\ Dhirendra Singh Yadav 5 \\ 'Department of Forensic Medicine and \\ Toxicology, Gauhati Medical College and \\ Hospital, Guwahati, Assam, India; \\ ${ }^{2}$ Department of Forensic Medicine and \\ Toxicology, Assam Medical College and \\ Hospital, Dibrugarh, Assam, India; \\ ${ }^{3}$ Department of Microbiology, All India \\ Institute of Medical Sciences, Rishikesh, \\ Uttarakhand, India; ${ }^{4}$ Department of \\ Radiology, FAAMC and Hospital, Barpeta, \\ Assam, India; ${ }^{5}$ Central Forensic Science \\ Laboratory, Directorate of Forensic \\ Science Services, Ministry of Home \\ Affairs, Government of India, Bhopal, \\ India
}

Correspondence: Putul Mahanta

Department of Forensic Medicine and Toxicology, Assam Medical College and Hospital, Dibrugarh, Assam, 786002, India Tel +919435017802

Email drpmahanta@gmail.com
Purpose: Death due to acute poisoning is one of the significant health challenges to copeup. It is imperative to know the death victims' pattern due to acute poisoning to prepare the relevant preventive and remedial measures. Therefore, the present study aimed to assess the pattern of the dead victims of acute poisoning in a tertiary care centre.

Materials and Methods: It is a hospital record-based study and conducted in a tertiary care centre. Descriptive statistics to study the distribution of the cases among different age groups, sex, type of poison compounds was computed and analysed using SPSS software version 20. Results: The present study detected poisonous substances in $244(41.8 \%)$ cases out of 584 death cases of suspected acute poisoning with the male preponderance of $62.29 \%$. A higher incidence of acute poisoning was noticed among the young age group 21-30 years (33.6\%) with $48(31.6 \%)$ cases among males and $34(36.9 \%)$ cases of the female. The Organophosphates (OP) was the main compound found in $151(61.9 \%)$ fatal cases, followed by Carbamate in $45(18.4 \%)$ cases. We also observed a maximum, $76(36.2 \%)$ cases of suicidal victims in the age group of 21-30 years. Children and lower age group were more vulnerable to accidental poisoning as $26.5 \%$ cases of accidental death were reported in both the age group of $0-10$ and 11-20 years respectively, gradually declining and practically found nil in above 60 years group. These differences of frequencies were found statistically significant $(\mathrm{p}<0.0001), \chi^{2}=55.1$.

Conclusion: The results suggest due consideration to the young adolescents' groups without any sexual discrimination to define guidelines for appropriate handling, storage and transportation of the poisonous compounds. Organophosphate's involvement as the most preferred agent in acute poisoning is to be remembered to help manage poisoning cases.

Keywords: organophosphates, socio-demographic variation, nature of poisoning, agriculture poisoning

\section{Introduction}

The recent literature review revealed acute poisoning as one of the most typical causes of hospital admission in the emergency department ${ }^{1,2}$ and a leading cause of morbidity and mortality in India and also a significant health problem worldwide. $^{3-6}$

The act of deliberate self-harm or accidental or homicidal ingestion of harmful substances that causes ill-health, injury or death into the body by different means may cause acute poisoning. Many preferred to die by poisoning for a peaceful death instead of passing by hanging or burning. ${ }^{4}$ Still, it could have been avoided with the 
appropriate intervention if measures are taken to avert them. $^{7}$ On usual, the yearly worldwide suicide rate is 10.5 per lakh population. ${ }^{8}$ Most of the review shows insecticides and pesticides to be the most widely used agents for poisoning. 4

Further, the North-eastern state being agriculturebased, pesticides are readily accessible, which also help many to a preferred mode of death. Rapid industrialisation and progress in the agricultural field have also made several other insecticides available, and exposure to these substances may cause poisoning. ${ }^{9,10}$ For enabling prevention and proper life-saving measures, the knowledge of the intention of the act and the type of poisoning is essential. ${ }^{3}$

Moreover, death due to poisoning is regarded as unnatural and requires medico-legal investigation and a postmortem examination. ${ }^{11}$ The socioeconomic status, religious and cultural influences, and the availability of poisons determine the pattern of poisoning, which will help to manage the

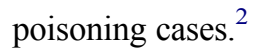

The current knowledge base for acute poisoning cases is still inadequate in this region. The research done, even-if exemplified an essential aid to our knowledge on the issue of acute poisoning, does not resolve the difficulties faced by us in determining the detailed profile of poisoning over a different population. We, therefore, evaluated the pattern of the subjects following acute poisoning in this underdeveloped region.

\section{Materials and Methods}

A retrospective hospital record-based study design was conducted on 584 death victims of suspected acute poisoning carried by the police to the Department of Forensic Medicine and Toxicology, Gauhati Medical College, Guwahati for the required medico-legal autopsy. The samples (viscera and blood) collected during the autopsy were sent for chemical analysis to the State Government Directorate of Forensic Science Laboratory (DFSL) to detect poison. The poisoning data acquired from the reports generated by DFSL. Socio-demographic data were obtained from the autopsy report and other medical records.

\section{Inclusion and Exclusion Criteria of Autopsy Reports for the Study}

All those cases which belonged to the Greater Kamrup region of Assam, India, with the features of acute poisoning were included in this study. Decomposed bodies, subjects with concomitant fatal injuries or co-morbidities were excluded from this study.

\section{Detection of Poison in the Laboratory}

The analysis was primarily done on viscera samples for the detection of poison. The blood samples were preserved of the patient hospitalised, prolonging the death that resulted in the ingested poison's metabolism. Also, blood samples preserved in suspected cases of drug and alcohol poisoning.

The types of poison consumed by the victim were determined using presumptive tests (colour tests and Thin Layer Chromatography-TLC) followed by confirmation using Gas Chromatography-Mass Spectrophotometry (GC-MS). Determination of alcohol in blood was done by head space gas chromatographic method. The same GC-MS drug-testing approach, known as "Gold standard", was used to confirm drug ingestion. Before this process, rapid immunoassay method was used to eliminate most of the negative samples. Methods used were validated and the laboratory results thus generated at DFSL are accepted by the courts of law in India.

\section{Status of Laboratory Reporting on the Detection of Poison}

Positive: The samples gave a positive test result for poison. Negative: No toxin was detected in the preserved samples, despite having positive autopsy findings for acute poisoning. The reasons for negative laboratory result of clinically positive cases of poisoning in this part of India are as follows: ${ }^{12}$ (i) Late examination because of the cases' long pendency. The long-time gap between sample collection and the laboratory analysis results in converting the original compound into undetectable by-product. (ii) Inappropriate preservation of the samples. (iii) Wastage of time on transportation in high temperature and humid environment spoiling the samples. (iv) Use of incorrect analytical methods. (v) Initial decomposition of poisons. (vi) Full metabolism of toxins before death. (vii) Presence of a negligent amount of poison in the samples due to initial treatment and (viii) Lack of infrastructures or equipment for testing certain toxins. Unknown: Unknown status of poisoning due to pending reporting of samples. Due to the samples' massive rush to the only authorised laboratory in this region, it takes time to examine and document.

\section{Manner of the Death}

The manner of death of these cases of death in the current study whether it is suicidal, homicidal or accidental was decided based on the (i) history given by the patients at the time of admission, (ii) history from the deceased relatives 


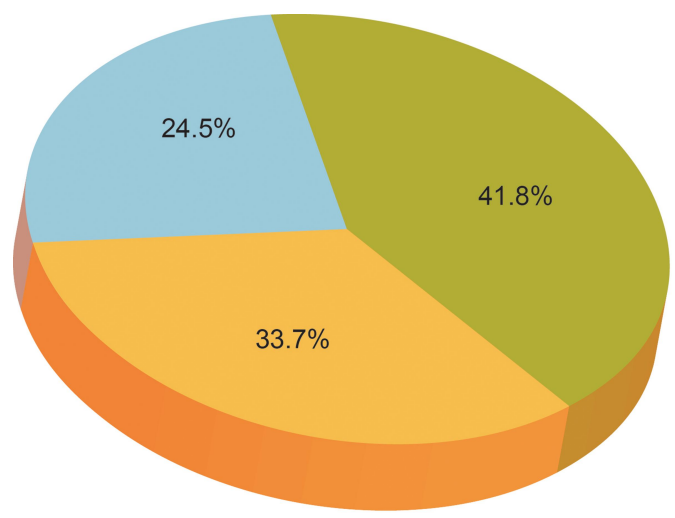

Positive reporting of poison

Negative reporting of poison

Unknown (Pending reporting of poison)

Figure I Distribution of cases with their status of poisoning report.

in cases of brought dead, (iii) autopsy findings, (iv) type of the poison detected and (iv) police investigation report.

\section{Statistical Analysis}

Detailed statistical analysis of the socio-demographic variables was done using Statistical Package for the Social Sciences (SPSS) software version 20. Descriptive statistical methods were used to study the incidence pattern of acute poisoning cases among different demographic and epidemiological variables. The chi-square test was used to test significant differences among categorical variables under study. A p-value of less than 0.05 was considered statistically significant. The ethical clearance was taken from the ethics committee, viz., "Institutional Ethics Committee" of Gauhati Medical College and Hospital, Guwahati, Assam and India (MC/190/2017/Pt-1/IEC/11 dated 05/04/2018) before collecting the data.

\section{Results}

Out of 584 reported suspected acute poisoning cases, 244 (41.8\%) were confirmed for poisoning by laboratory tests. At the same time, $33.7 \%$ of cases were negative for poisonous substances at laboratory tests though they were found positive at autopsy findings. Also, $24.5 \%$ of the suspected poisoning cases were awaiting laboratory test reports, and their status was unknown during our study period, as shown in Figure 1. The present study considered the 244 laboratory-confirmed acute poisoning cases for further analysis.

Males subject was predominant in acute poisoning cases with $152(62.29 \%)$ out of 244 cases compared to females 92 (37.7\%).

The analysis reports the highest incidence of acute poisoning cases among young individuals as 82 (33.6\%) positive cases of acute poisoning belonged to the age group of 21-30 years with 48 (31.6\%) male and 34 (36.9\%) females. However, the differences in frequency between males and females among different age groups were not statistically significant $(p=0.84), \chi^{2}=2.7$ (Table 1).

Table 2 shows the types of poisons detected on laboratory examination of the viscera and blood samples preserved during dead victims' autopsy following acute poisoning. Organophosphate was accounted for most acute poisoning deaths in $151(61.9 \%)$ cases followed by carbamate compound in $45(18.4 \%)$ cases.

Table I Age-Wise Distribution of Positive Cases of Poisoning

\begin{tabular}{|c|c|c|c|c|c|c|}
\hline Age in Years & Total No. of Cases & Male & Percentage \% & Female & Percentage \% & Total \% \\
\hline $0-10$ & 9 & 7 & 4.6 & 2 & 2.1 & 3.7 \\
\hline $1 \mathrm{I}-20$ & 23 & 15 & 9.9 & 8 & 8.7 & 9.4 \\
\hline $21-30$ & 82 & 48 & 31.6 & 34 & 36.9 & 33.6 \\
\hline $31-40$ & 70 & 43 & 28.3 & 27 & 29.3 & 28.7 \\
\hline $4 I-50$ & 47 & 29 & 19.1 & 18 & 19.6 & 19.3 \\
\hline $5 I-60$ & 8 & 6 & 3.9 & 2 & 2.2 & 3.3 \\
\hline$>60$ & 5 & 4 & 2.6 & I & 1.1 & 2.0 \\
\hline Total & 244 & 152 & 100 & 92 & 100 & 100 \\
\hline
\end{tabular}


Table 2 Type of Poisons Detected During the Chemical Examination

\begin{tabular}{|l|l|l|}
\hline Types of Poison & $\begin{array}{l}\text { Number of } \\
\text { Cases }\end{array}$ & $\begin{array}{l}\text { Percentage (\%) of } \\
\text { Cases }\end{array}$ \\
\hline Organophosphates & 151 & 61.9 \\
Carbamate & 45 & 18.4 \\
Organochlorine & 23 & 9.4 \\
Nitric Acid & 17 & 7.0 \\
Oxalic acid & 08 & 3.3 \\
Total & 244 & 100 \\
\hline
\end{tabular}

The maximum number of $76(36.2 \%)$ cases was suicidal and found in 21 to 30 years. Higher deaths [n=9 (26.5\%)] following accidental poisoning were seen in the age group of $0-10$ and $11-20$ years, gradually declining and practically found nil in above 60 . Unintentional death cases were observed mostly among lower age groups, whereas most suicidal poisoning cases were observed among young and adult age groups. These differences of frequencies were found to be statistically significant ( $p<0.0001), \chi^{2}=55.1$. We did not find homicidal cases in the present study (Table 3 ).

Figure 2 shows the socio-demographic distribution (location) of the cases of poisoning. Majority of the poisoning cases belong to the rural areas, i.e., 154 (63.1\%) outnumbered $90(36.9 \%)$ of the urban regions.

Figure 3 represents the seasonal variation of acute poisoning cases. The current study reported a maximum of $91(37.3 \%)$ cases of death in the summer season, followed by the autumn season for $70(28.7 \%)$ cases.

\section{Discussion}

India's north-east part is an agricultural and developing region with many rural inhabitants where the agricultural poisons are readily available. It may be the root cause of this higher frequency of death due to poisoning.

Table 3 Manner of Death of the Acute Poisoning Cases

\begin{tabular}{|l|c|c|c|c|}
\hline $\begin{array}{l}\text { Age in } \\
\text { Years }\end{array}$ & $\begin{array}{c}\text { Accidental } \\
\text { Poisoning }\end{array}$ & $\%$ & $\begin{array}{c}\text { Suicidal } \\
\text { Poisoning }\end{array}$ & $\%$ \\
\hline $0-10$ & 09 & 26.5 & 0 & 0 \\
$\mathrm{II}-20$ & 09 & 26.5 & 14 & 6.7 \\
$2 \mathrm{I}-30$ & 06 & 17.6 & 76 & 36.2 \\
$3 \mathrm{I}-40$ & 06 & 17.6 & 64 & 30.5 \\
$4 \mathrm{I}-50$ & 03 & 8.8 & 44 & 20.9 \\
$5 \mathrm{I}-60$ & $0 \mathrm{I}$ & 2.9 & 07 & 3.3 \\
$>60$ & 0 & 0 & 05 & 2.4 \\
Total & 34 & 100 & 210 & 100 \\
\hline
\end{tabular}

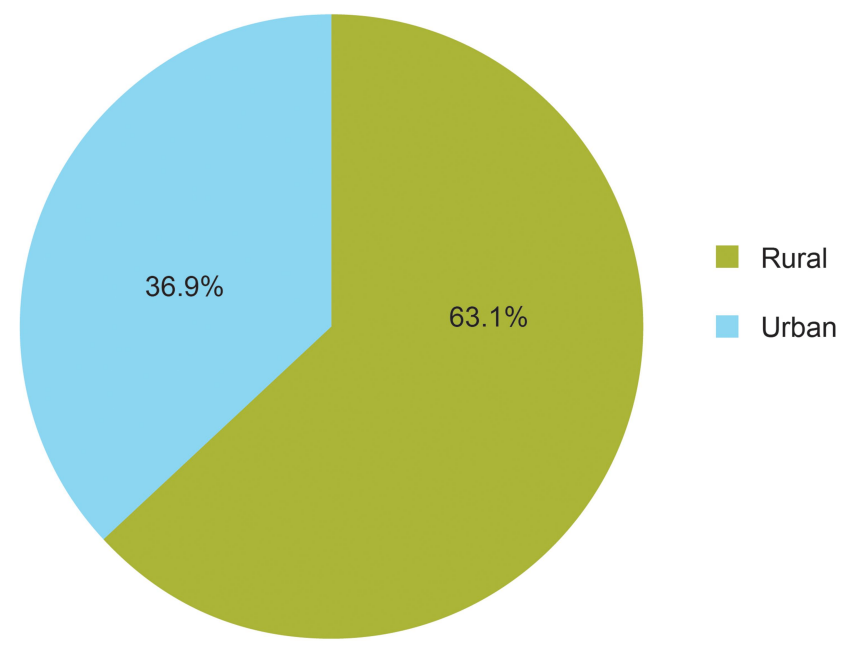

Figure 2 Socio-demographic distribution (location) of the cases of acute poisoning. No of the cases (\%)

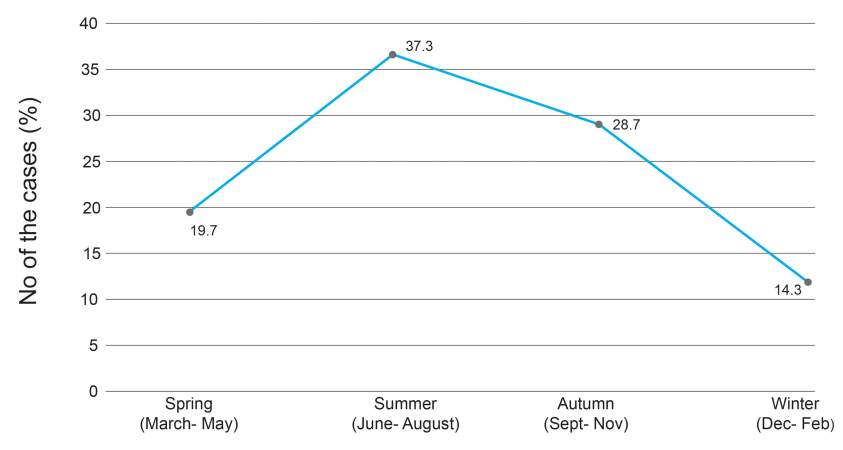

Figure 3 Seasonal variation of the poisoning cases.

The current study's male preponderance has some support from recent reviews, ${ }^{4,11}$ which reported a similar distribution of male and female subjects with acute poisoning. However, some other studies said a higher male and female ratio of $3: 1 .^{13,14}$ Contradict to our result, Nepal ${ }^{15}$ has shown M: $F=1: 2$, Albania $^{16}$ as M: $F=0.09: 1$ and in Turkey and Ethiopia ${ }^{17,18}$ the M: F is about 1:1.47.

Many recent studies ${ }^{4,13,16,19}$ have reported younger age groups' involvement with acute poisoning similar to our results. This period of life is highly productive, as well as stressful. In this age group, individuals get an education and begin to earn to feed their family and be exposed to hazardous and stressful life challenges such as new jobs, settlement in marriage, and other social security causing psychological disturbances. Many times, due to the young adult's inability to cope with the increased stress and personality factors, they may cause deliberate self-harm. 
In contrast, another review ${ }^{20}$ revealed a high prevalence of death in 40-49 years of age.

Like the current study, Organophosphate as the commonly involved pesticide accounted for poisonous deaths compared to other compounds has also reported in some other reviews. ${ }^{13,21,22}$ Dash et al also observed the same result in his research on poisoning. ${ }^{21}$ In contrast, in a study conducted at New Delhi, India reported the drugs (18\%) and insecticides $(12.80 \%)$ as the ordinary agents in the poisoning cases. Other than the insecticide group, Carbamate formed the most extensive group, followed by Organophosphate, and organochlorine compounds have been revealed in that study. ${ }^{23}$ These variances in frequencies may be due to the differences in the pattern of use and the availability of poisonous substances.

The findings from other studies ${ }^{14,15,17,24}$ have supported a higher incidence of suicidal cases of the current study. However, a study has reported $72.02 \%$ of suicidal, $25.88 \%$ accidental and $2.10 \%$ of cases unknown, ${ }^{25}$ dissimilar to our result. The higher prevalence of cases from the rural areas reported in the present study well tallied with a review. ${ }^{21}$ This may be because of the playful handling of pesticidal substances because agriculture is a significant occupation for the people living in this rural region.

The seasonal variation of deaths found in the current study has some supportive reviews. A similar study, ${ }^{26}$ revealed that the highest number of cases occurred in the summer season ${ }^{11}$ with $48.51 \%$ cases followed by the winter season with $29.78 \%$ cases. $^{26}$

This study has some limitations for being retrospective and record-based and has missed some valued information like time-lapse to reach the hospital and a thorough psychiatric history.

\section{Conclusion}

Health education and strict legal intervention regarding storage, handling and transportation of poisonous substances to restrict the easy availability should be mandatory. Due consideration to the young adolescents' groups is to be made while preventive measures are defined. For quick and better management of the acute poisoning cases, a poison detection centre should be mandatory for each tertiary care centre with all modern machinery and trained staff.

Finally, there is a need to study further the high mortality rates associated with acute poisoning in this region. The concerned authority should also initiate suicide prevention policies for the adolescence and middle-aged people.

\section{Ethical Corrections}

All data of the cases were treated with confidentiality, following the declaration of Helsinki.

\section{Acknowledgments}

Thanks to the scientists at DFSL who helped us by providing reports of the samples. All departmental colleagues who helped us access the relevant medical records during the study were also acknowledged.

\section{Author Contributions}

All authors made a significant contribution to the work reported, whether that is in the conception, study design, execution, acquisition of data, analysis and interpretation; took part in drafting, revising or critically reviewing the article; gave final approval of the version to be published; have agreed on the journal to which the article has been submitted; and agree to be accountable for all aspects of the work.

\section{Disclosure}

The authors report no conflicts of interest in this work.

\section{References}

1. Bamathy B, Punnagai K, Amritha CA, et al. Incidence \& patterns of acute poisoning cases in an emergency department of a Tertiary Care Hospital in Chennai. Biomed Pharmacol J. 2017;10(3):1285-1291. doi: $10.13005 / \mathrm{bpj} / 1231$

2. Putul M. Modern Textbook of Forensic Medicine and Toxicology. New Delhi: Jaypee Brothers; 2014:554. ISBN 9789351522119.

3. Revathi D, Reddy S, Prasanna V L, et al. Patterns of acute poisoning among patients treated in the emergency wards of a tertiary care hospital: a cross-sectional study. Asian J Pharm Clin Res. 2018;11 (11):270. doi:10.22159/ajpcr.2018.v11i11.27422

4. Sharma R, Neelanjana RN, Rawat N, et al. Mortality and morbidity associated with acute poisoning cases in north-east India: a retrospective study. $J$ Family Med Prim Care. 2019;8 (6):2068-2072. doi:10.4103/jfmpc.jfmpc_237_19

5. Desalew M, Aklilu A, Amanuel A, et al. Pattern of acute adult poisoning at Tikur Anbessa specialized teaching hospital, a retrospective study, Ethiopia. Hum Exp Toxicol. 2011;30 (7):523-527. doi:10.1177/0960327110377520

6. WHO. Poisoning prevention and management. [cited November 30 2020]; Available from: https://www.who.int/ipcs/poisons/en/. Accessed February 5, 2021.

7. Wang B, Han L, Wen J, et al. Self-poisoning with pesticides in Jiangsu Province, China: a cross-sectional study on 24,602 subjects. Res Sq. 2020. doi:10.21203/rs.3.rs-39759/v2

8. Bachmann S. Epidemiology of suicide and the psychiatric perspective Int J Environ Res Public Health. 2018;15(7):1425. doi:10.3390/ ijerph15071425 
9. Singh RR, Kumar A, Uraiya D, et al. Retrospective analysis of poisoning cases admitted in a tertiary care hospital in North Eastern UP, India. Int J Med Res Rev. 2016;4(7):1172-1177. doi:10.17511/ ijmrr.2016.107.17

10. Alinejad S, Zamani N, Abdollahi M, et al. A narrative review of acute adult poisoning in Iran. Iran J Med Sci. 2017;42(4):327-346.

11. Das RK. Epidemiology of insecticide poisoning at AIIMS emergency services and role of its detection by gas-liquid chromatography in diagnosis. Med Legal Update. 2007;7:49-60.

12. Jaiswal AK, Gupta SK, Millo T, et al. Death is due to poisoning but viscera report is negative. Indian J Forensic Med Pathol. 2015;8 (1):29-36. doi:10.21088/ijfmp.0974.3383.8115.5

13. Saxena V, Atal DK, Das S. Retrospective analysis of the pattern of poisoning in Uttarakhand. $J$ Indian Acad Forensic Med. 2014;36:230-233.

14. Kumar MR, Kumar GPV, Kumar S, et al. A retrospective analysis of acute organophosphorus poisoning cases admitted to the tertiary care teaching hospital in South India. Ann Afr Med. 2014;13(2):71-75. doi:10.4103/1596-3519.129876

15. Rehiman S, Lohani SP, Bhattarai MC. Correlation of serum cholinesterase level, clinical score at presentation and severity of organophosphorous poisoning. J Nepal Med Assoc. 2018;47:47-52.

16. Sulaj Z, Prifti E, Demiraj A, et al. Early clinical outcome of acute poisoning cases treated in intensive care unit. Med Arch. 2015;69 (6):400-404. doi:10.5455/medarh.2015.69.400-404

17. Yurumez Y, Durukan P, Yavuz Y, et al. Acute organophosphate poisoning in university hospital emergency room patients. Intern Med. 2007;46(13):965-969. doi:10.2169/internalmedicine.46.6304
18. Adinew GM, Woredekal AT, DeVos EL, et al. Poisoning cases and their management in emergency centres of government hospitals in northwest Ethiopia. African $J$ Emerg Med. 2017;7(2):74-78. doi:10.1016/j.afjem.2017.04.005

19. Dhanya SP, Dhanva TH, Latha RNB, et al. A retrospective analysis of the pattern of poisoning in patients admitted to medical college hospital. Calicut Med J. 2009;7:e3.

20. Chakrabarty P, Tudu NK, Saren AB, et al. Epidemiology of unnatural death from suspected poisoning: an autopsy based study. IOSR J Dent Med Sci. 2015;14(8):1-8.

21. Dash SK, Raju AS, Mohanty MK, et al. Socio-demographic profile of poisoning cases. J Indian Acad Forensic Med. 2005;27(3):133-138.

22. Gupta P, Kumar A, Singh SP, et al. pattern of cases of acute poisoning in a rural tertiary care center in Northern India. Community Med. 2016;7:307-310.

23. Gopal BK, Viswanath B, Shruthi P, et al. A retrospective analysis of suicidal poisoning deaths in a metropolitan city of South India. $J$ Indian Acad Forensic Med. 2015;37(2):140.

24. Singh J, Kaur J, Kumar V, et al. Trends of poisoning in a tertiary care centre of Northwest UP. J Indian Acad Forensic Med. 2015;37 (4):396-399. doi:10.5958/0974-0848.2015.00103.7

25. Patel DJ, Tekade PR. Profile of organophosphorus poisoning at maharani hospital, Jagdalpur, Chhattisgarh: a three years study. J Indian Acad Forensic Med. 2011;33:102-105.

26. Varma NM, Kalele SD. Study of profile of deaths due to poisoning in Bhavnagar region. J Indian Acad Forensic Med. 2011;33(2):106-108.

\section{Publish your work in this journal}

The Open Access Emergency Medicine is an international, peerreviewed, open access journal publishing original research, reports, editorials, reviews and commentaries on all aspects of emergency medicine. The manuscript management system is completely online and includes a very quick and fair peer-review system, which is all easy to use. Visit http://www.dovepress.com/testimonials.php to read real quotes from published authors. 